\title{
Pessoas vivendo com HIV e mudanças na rotina diária decorrentes da pandemia da COVID-19
}

\author{
People living with HIV and changes in the daily routine arising from the COVID-19 pandemic \\ Personas que viven con HIV y cambios en la rutina diaria derivados de la pandemia COVID-19
}

Tassiana Maria Vieira Pereira ${ }^{1}$ (D)

Elucir $\mathrm{Gir}^{1}$

Andressa Silva Torres dos Santos ${ }^{1}$ (D)

1. Universidade de São Paulo, Programa de Pós-graduação em Enfermagem Fundamental. Ribeirão Preto, SP, Brasil.
Autor correspondente

Tassiana Maria Vieira Pereira.

E-mail: vieiraematos@yahoo.com.br.

Recebido em 27/04/2021.

Aprovado em 06/07/2021.

\section{Resumo}

Objetivo: identificar as mudanças na rotina das pessoas vivendo com HIV decorrentes da pandemia da COVID-19. Método: pesquisa qualitativa, desenvolvida por meio de entrevista semiestruturada, junto à 46 pessoas vivendo com HIV atendidas em um serviço especializado em doenças infectocontagiosas do interior de Minas Gerais, Brasil. Os dados foram submetidos à análise lexicográfica, com auxílio do software IRaMuTeQ, pelos métodos de Estatística Textual Clássica, Nuvem de Palavras e Classificação Hierárquica Descendente. Resultados: foram identificadas distintas mudanças na rotina diária de pessoas vivendo com HIV decorrentes da pandemia da COVID-19, dentre elas, o uso de medidas preventivas, como a utilização de máscara e isolamento social, além de mudanças no ambiente de trabalho e de lazer, no convívio familiar, aspectos emocionais individuais e de tratamento. Conclusão e implicações para a prática: muitas mudanças e desafios de ordem física, biológica e psicossocial demonstraram serem vivenciados pelos participantes diante do cenário mundial pandêmico, decorrentes, principalmente, do isolamento social. Para tal, estratégias de enfrentamento tornam-se fundamentais no dia-a-dia das pessoas vivendo com HIV visando garantir a continuidade e tratamento ininterrupto, e a prevenção de uma sindêmia, mitigando, assim, as repercussões da COVID-19 na saúde destes indivíduos que pertencem ao grupo de risco.

Palavras-chave: Coinfecção; Infecções por Coronavirus; Infecções por HIV; Pandemias; Isolamento Social.

\section{Abstract}

Objective: to identify the changes in the routine of people living with HIV resulting from the COVID-19 pandemic. Method: a qualitative research study, developed through a semi-structured interview, with 46 people living with HIV treated at a service specialized in infectious diseases in the inland of Minas Gerais, Brazil. The data were submitted to lexicographic analysis, with the aid of the IRaMuTeQ software, using the methods of Classical Textual Statistics, Word Cloud and Descending Hierarchical Classification. Results: distinct changes were identified in the daily routine of people living with HIV due to the COVID-19 pandemic, including the use of preventive measures, such as wearing a mask and social isolation, in addition to changes in the work and leisure environment, in family life, individual emotional aspects and treatment. Conclusion and implications for the practice: many changes, challenges of a physical, biological and psychosocial nature have been shown by the participants in the face of the global pandemic scenario, mainly resulting from social isolation. To this end, coping strategies become essential in the everyday lives of people living with HIV in order to guarantee continuity and uninterrupted treatment, and the prevention of a syndemic, thus mitigating the repercussions of COVID-19 on the health of the individuals who belong to the risk group.

Keywords: Coinfection; Coronavirus Infections; HIV Infections; Pandemics; Social Isolation.

\section{Resumen}

Objetivo: identificar los cambios en la rutina de las personas que viven con VIH como resultado de la pandemia de COVID-19. Método: investigación cualitativa, desarrollada a través de una entrevista semiestructurada, con 46 personas que viven con $\mathrm{VIH}$ atendidas en un servicio especializado en enfermedades infecciosas en el interior de Minas Gerais, Brasil. Los datos fueron sometidos a análisis lexicográfico, con la ayuda del software IRaMuTeQ, y utilización de los métodos de Estadística Textual Clásica Nube de Palabras y Clasificación Jerárquica Descendente. Resultados: se identificaron distintos cambios en la rutina diaria de las personas que viven con VIH debido a la pandemia de COVID-19, incluido el uso de medidas preventivas, como la utilización de barbijo y aislamiento social, además de cambios en el entorno laboral y de ocio, en la vida familiar, en aspectos emocionales individuales y en el tratamiento. Conclusión e implicaciones para la práctica: muchos cambios y desafíos de naturaleza física, biológica y psicosocial han atravesado a los participantes ante el escenario de la pandemia global, principalmente debido al aislamiento social. Para ello, las estrategias de afrontamiento se vuelven imprescindibles en el día a día de las personas que viven con VIH a fin de garantizar la continuidad y el tratamiento ininterrumpido, y la prevención de una sindemia, con el objetivo de mitigar las repercusiones del COVID-19 en la salud de estos sujetos que pertenecen al grupo de riesgo.

Palabras clave: Coinfección; Infecciones por Coronavirus; Infecciones por VIH; Pandemias; Aislamiento Social. 


\section{INTRODUÇÃO}

A pandemia da doença do coronavírus 2019 (COVID-19) até junho de 2021 ocasionou mais de 176 milhões de casos confirmados e 3 milhões de óbitos no mundo ${ }^{1}$. A rápida disseminação do vírus Severe Acute Respiratory Syndrome Coronavírus 2 (SARS-CoV-2) e o aumento exponencial de contágio geraram sérios impactos de ordem sanitária, social, econômica e política para as nações ${ }^{2}$, com consequente mudança na rotina de toda a população.

Dentre os mais afetados pelas infecções por coronavírus, destacam-se os indivíduos que pertencem ao grupo de risco, decorrente de doenças crônicas; a exemplo os imunocomprometidos, como as pessoas vivendo com HIV (PVHIV), que apresentam maior risco de exposição e agravamento da doença diante da coinfecção ${ }^{3}$.

A implementação da quarentena, distanciamento e isolamento social, e demais medidas preventivas constituem as principais mudanças nos hábitos da população. $\mathrm{O}$ isolamento social, especificamente, por si só representa um fator de risco para problemas de saúde na população em geral, visto que pode aumentar drasticamente os sentimentos de isolamento e solidão no período da pandemia, o que pode ser exacerbado por desafios específicos enfrentados pelas PVHIV, que devem tomar precauções extras, além de manter o tratamento recomendado ${ }^{3,4}$, de forma a se adaptarem ao cenário atual.

Logo, inúmeras foram as mudanças na rotina da população diante dessa pandemia. Assim, este estudo apresenta os seguintes questionamentos a serem atendidos: houve mudança na rotina diária de PVHIV após a pandemia da COVID-19? O que mudou na rotina diária desses indivíduos?

Estudos primários que apontem tais mudanças, especificamente entre PVHIV, não foram localizados em distintos recursos informacionais da área da saúde, tendo em vista a contemporaneidade da situação mundial. Portanto, é válida toda iniciativa que busque agregar novas evidências que colaborem na identificação do enfrentamento da pandemia pelas PVHIV, o que justifica a realização desse estudo. Desse modo, o objetivo da pesquisa foi identificar as mudanças na rotina das PVHIV decorrentes a pandemia da COVID-19.

\section{MÉTODO}

Pesquisa descritiva, de abordagem qualitativa, junto a PVHIV atendidas em um serviço especializado em doenças infectocontagiosas do interior de Minas Gerais. O serviço é sede da microrregião e referência para 12 municípios adjacentes. Os critérios de inclusão foram: ter idade superior a 18 anos e ciência do diagnóstico confirmado do vírus da imunodeficiência humana (HIV) há no mínimo 6 meses.

Os participantes foram abordados e convidados a participar do estudo, pessoalmente, pela pesquisadora no dia da consulta médica, entrega de medicamentos de uso contínuo ou outras demandas, respeitando sua disponibilidade e o aceite em participar da pesquisa. Vale destacar que durante toda a coleta de dados ocorreram duas recusas de participação após a abordagem de pretensos participantes com relato de dor e compromisso agendado não dispondo, assim, de horário disponível. O número de participantes foi delimitado, no decorrer do trabalho de campo, pela saturação teórica dos dados ${ }^{5}$, visando atingir o objetivo do estudo, respeitando o mínimo de 20-30 textos recomendado pelo software de processamento dos dados ${ }^{6}$. A amostra foi constituída por conveniência.

Os dados foram coletados no período de julho a setembro de 2020, por meio de entrevista semiestruturada realizada em um consultório médico da unidade de pesquisa, um ambiente tranquilo e privado que se encontrava disponível no momento das coletas, respeitando a rotina e o funcionamento do serviço. Para tal, foi utilizado um instrumento semiestruturado, composto por duas partes, construído pela equipe de pesquisa e avaliado qualitativamente por três especialistas na temática no que se refere à validade de face e conteúdo. A primeira parte contou com questões fechadas referentes à caracterização do perfil dos participantes, a saber: município de residência, idade, sexo, orientação sexual, situação maritária e escolaridade. A segunda parte contemplou a seguinte pergunta norteadora da entrevista: Mudou algo na sua rotina diária após a pandemia da COVID-19?

As entrevistas foram gravadas em mídia digital, com duração média de 23,54 minutos, e transcritas na íntegra pela pesquisadora principal, constituindo a fonte primária de dados que foi devidamente preparada e processada por análise lexicográfica do corpus textual, por meio do software Interface de $R$ pour Analyses Multidimensionnelles de Textes Et de Questionnaires (IRaMuTeQ), pelos métodos de Estatística Textual Clássica, Nuvem de Palavras e Classificação Hierárquica Descendente (CHD) ${ }^{6}$.

Para tal, foram resgatadas as formas ativas das classes de segmentos de texto (substantivos, adjetivos, advérbios, verbos e formas não reconhecidas), que obtiveram no teste qui-quadrado (Qui ${ }^{2}$ ) um valor $\geq 3,84$, logo, $p<0,05$, com destaque para aquelas com um $p<0,0001$, visto que indicaram uma forte associação entre as palavras na sua respectiva classe. A partir disso, a interpretação dos dados foi baseada nos pressupostos metodológicos da Análise Temática de Conteúdo7 .

Para análise da caracterização dos participantes, referentes às perguntas fechadas contidas na primeira parte do instrumento, os dados foram submetidos ao software IBM® Statistical Package for the Social Sciences trial version 25.0, mediante estatística descritiva com cálculos de frequência absoluta e relativa, e média.

Estudo aprovado pelo Comitê de Ética e Pesquisa da Escola de Enfermagem de Ribeirão Preto da Universidade de São Paulo. Todos os participantes foram esclarecidos, assinaram e receberam cópia do Termo de Consentimento Livre e Esclarecido (TCLE). Para o anonimato, foi utilizado um código alfanumérico (P-participante) mediante a ordem de participação.

\section{RESULTADOS}

Participaram do estudo 46 PVHIV, sendo 31 (67,4\%) do sexo masculino e $15(32,6 \%)$ do sexo feminino. A faixa etária compreendeu participantes de 18 A 65 anos, com média de 
idade 42,62 anos. Quanto à orientação sexual, $54,3 \%$ se referem heterossexuais, $37 \%$ homossexuais, $4,3 \%$ bissexuais e $4,3 \%$ transsexuais. Ainda, $41,3 \%$ dos participantes declararam-se solteiros, $26,1 \%$ em situação de união estável, $15,2 \%$ casados, $10,9 \%$ divorciados/separados e $6,5 \%$ viúvos.

A maioria, $71,7 \%$, dos participantes reside no município sede da microrregião, enquanto $28,3 \%$ residem nos municípios circunvizinhos. Quanto à escolaridade, 32,6\% possuem ensino fundamental ou médio completo, seguido de 10,9\% com fundamental incompleto ou superior completo, e, $13 \%$ com pós-graduação.

O corpus textual geral, após o processamento pelo software de análise, pela estatística básica, foi constituído por 46 textos separados em 142 segmentos de textos (ST) e 4748 ocorrências de palavras, sendo 1081 palavras distintas e 626 hápax, com uma média de 103,22 vocábulos por texto.

Pelo método da Nuvem de Palavras, identificaram-se os termos de maior recorrência e relevância no corpus textual, com base na frequência, sendo os que se exibem maiores e mais dispostos centralmente que os demais na Figura 1. Nessa diretiva, as dez formas ativas mais frequentes nas respostas correlacionadas às mudanças na rotina em investigação, por ordem de ranqueamento, foram: não ( $f=149)$, estar ( $f=106)$, gente $(\mathrm{f}=73)$, porque $(\mathrm{f}=66)$, mais $(\mathrm{f}=62)$, ficar $(\mathrm{f}=55)$, casa $(\mathrm{f}=50)$, já $(\mathrm{f}=45)$, coisa $(\mathrm{f}=44)$ e muito $(\mathrm{f}=44)$.

O emprego desses termos está relacionado às principais mudanças na rotina das PVHIV, sendo uma delas o isolamento social, o fato de não poder sair de casa, estar em espaços aglomerados ou realizar atividades que anteriormente eram comuns no dia-a-dia. Ainda, o advérbio "não" descreve o sentido das restrições impostas às pessoas com a pandemia, enquanto o termo "porque" busca

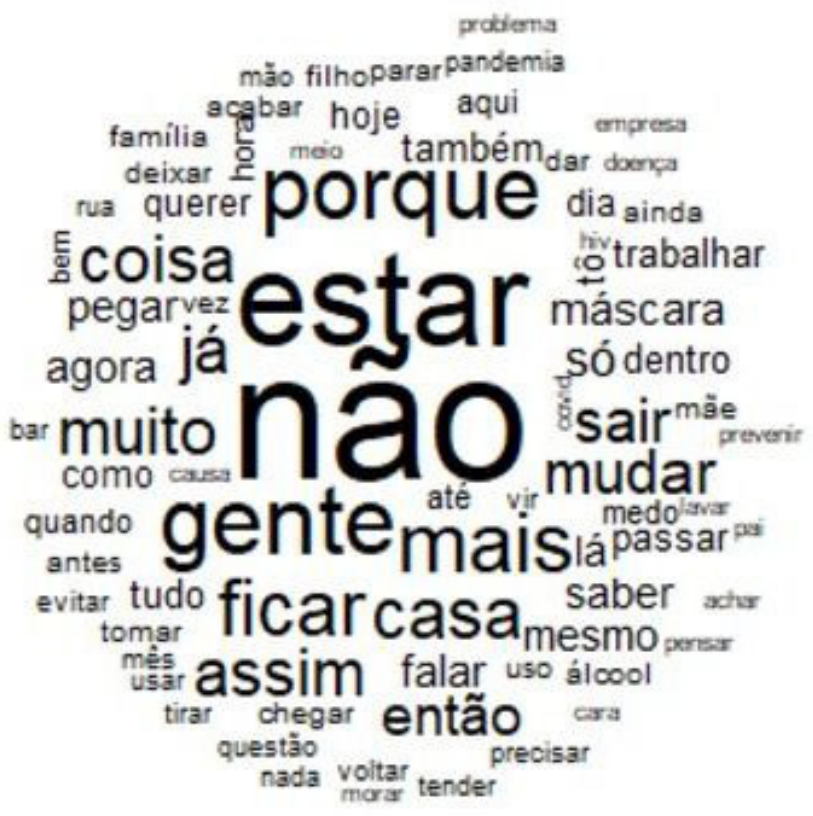

Figura 1. Nuvem de Palavras. Minas Gerais, MG, Brasil, 2020. Fonte: Obtido com a aplicação do Software IRaMuTeQ. explicar o porquê de determinadas práticas e a palavra "muito" denota, principalmente, que houve muitas mudanças.

Posteriormente, através da CHD foi possível um aprofundamento para a compreensão do objeto investigado, que classificou 115 dos segmentos de textos retidos, logo, obteve um aproveitamento de $80,99 \%$, que por meio do agrupamento quanto à ocorrência de palavras gerou seis classes de segmentos de textos. A lematização resultou em 774 lemas (formas reduzidas) com 668 formas ativas. O dendrograma da Figura 2 sintetiza as classes, mostrando as palavras com força associativa confirmada, através do teste quiquadrado (Qui2 $\geq 3,84$ ), a relação entre as classes e o percentual destas em relação ao total do corpus analisado.

No dendrograma, o corpus textual dividiu-se em dois subcorpus independentes. O primeiro composto pela classe $1(17,4 \%)$ da qual derivam outras 4 ramificações menores, sendo a primeira subdivisão, com associação de vocábulos entre si, as classes $2(17,7 \%)$ e $3(13,9 \%)$, e a segunda com as classes $4(12,2 \%)$ e $5(26,1 \%)$. Ainda, o segundo subcorpus é composto somente pela classe $6(14,8 \%)$, que se opõe às outras classes em termos lexicais.

A partir disso, as classes e seus respectivos segmentos de textos resgatados foram analisados e interpretados minuciosamente a fim compreender os núcleos de sentido e nominar cada uma delas, conforme descrito a seguir.

\section{Classe 1 - Ciência da exposição à COVID-19 em um contexto sindêmico com o HIV}

A classe 1 foi responsável por $17,4 \%$ dos segmentos de texto, na qual a forma ativa que apresentou uma associação extremamente significativa $\left(Q_{u}{ }^{2} \geq 3,84\right.$ e $\left.p<0,0001\right)$ foi: também,

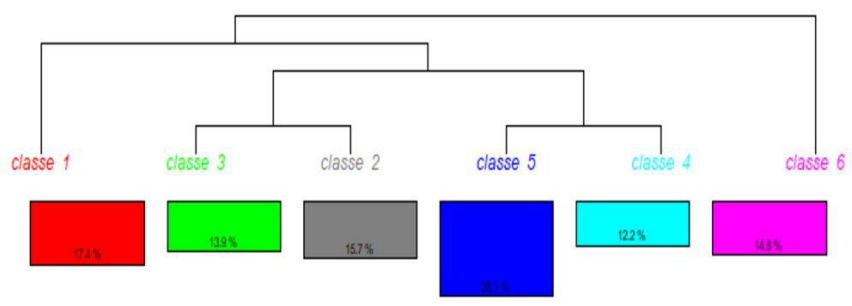

\begin{tabular}{|c|c|c|c|c|c|}
\hline também & morar & dentro & rua & passar & mão \\
\hline ainda & irmạão & aO & vez & querer & chegar \\
\hline problema & pai & casa & máscara & via & lavar \\
\hline ugar & então & dar & buscar & plor & doença \\
\hline saúde & mais & tirar & antes & $\begin{array}{l}\text { entender } \\
\text { normal }\end{array}$ & banho \\
\hline voltar & mäe & sair & bar & dificil & lá \\
\hline $\begin{array}{l}\text { falar } \\
\text { tender }\end{array}$ & $\begin{array}{l}\text { Tamilla } \\
\text { filho }\end{array}$ & $\begin{array}{l}\text { praticament } \\
\text { amico }\end{array}$ & $\begin{array}{l}\text { trabalhar } \\
\text { começo }\end{array}$ & $\begin{array}{l}\text { mundo } \\
\text { empreco }\end{array}$ & álcool \\
\hline questão & sozinho & & mesmo & & prevenir \\
\hline cuidado & & mudar & vir & & meio \\
\hline arrumar & dentro & sim & usar & agora & roupa \\
\hline & assim & receber & sair & pandemla & negócio \\
\hline udanca & relação & preso & estar" & coisa & menino \\
\hline & $\begin{array}{l}\text { Incomodar } \\
\text { ansiedade }\end{array}$ & mercado & $\begin{array}{l}\text { Causa } \\
\text { porque }\end{array}$ & & $\begin{array}{l}\text { nora } \\
\text { iqual }\end{array}$ \\
\hline & acontecer & & & & ara \\
\hline & mercado & & começar & & \\
\hline
\end{tabular}

Figura 2. Dendrograma da Classificação Hierárquica Descendente. Minas Gerais, MG, Brasil, 2020.

Fonte: Resultado da aplicação no Software IRaMuTeQ. 
ainda e problema. Contudo, outros vocábulos também apresentam conexidade entre esses termos (Qui ${ }^{2} \geq 3,84$ ), dentre os principais, em ordem decrescente: lugar, saúde e voltar.

Os termos destacados nesta classe se remetem às mudanças e a compreensão da exposição à COVID-19 em um contexto sindêmico com infecções por HIV. A palavra em evidência "também" expõe o entendimento das medidas de prevenção que os participantes têm utilizado, como evitar os lugares com aglomeração, reconhecendo, assim, suas vulnerabilidades.

Evito de ficar indo nos lugares muito cheios. Os cuidados. Evito de ficar perto de muita gente também. Porque eu penso assim, eu não posso pegar isso aí porque senão a minha casa cai (P34).

A palavra "também" relata algumas dificuldades encontradas no período de pandemia relacionadas, principalmente, ao acesso aos serviços de saúde no tratamento de doenças oportunistas, visto que as PVHIV utilizam sistema público de referência em diversas especialidades. O surgimento dessas doenças, comumente presente junto às PVHIV, traz uma demanda de atendimento e avaliação de especialidades que geralmente não estão agregadas ao Centro de Testagem e Aconselhamento e ao Serviço de Assistência Especializada (CTA/SAE), porém, fazem parte do Sistema Único de Saúde (SUS). Uma parte destas especialidades que atuam num contexto ambulatorial e interpretadas pelos gestores como eletivas, sofreram restrição de atendimento no período pandêmico, conforme a fala sinalizada a seguir:

Mudou também na questão de atendimento médico. [...] Aqui no CTA não. Mas já aconteceu de eu precisar de vir aqui no CTA e ter encaminhamento pra fazer em outro hospital e nesse outro hospital falaram comigo que não iriam fazer, porque eu precisava fazer tipo uma mini cirurgia, e falaram que não poderiam fazer (P14).

Ainda a exemplo disso, o participante relatou o atraso no tratamento de uma doença oportunista diagnosticada, o Papilomavírus Humano (HPV).

Se eu não trato, com o tempo, pode evoluir e pode virar até um câncer. Então precisa fazer essa cirurgia. Que até hoje eu não fiz e eu vou até lá e a médica falou na minha cara o seguinte: A gente não tá fazendo tratamento em pessoas que não tem câncer ainda. A gente está fazendo cirurgias em pessoas que estão à beira da morte, entendeu. Ou seja, ela simplesmente falou assim, espera você ter câncer que a gente vai fazer sua cirurgia. Isso foi o quê mais me incomodou ( $\mathrm{P} 14)$.

Este dado retrata as mudanças geradas pela pandemia no tratamento indireto de alguns participantes, visto que referem doenças secundárias ao HIV e que, se não tratadas, impactam na saúde desses indivíduos. Tal situação aconteceu com o fechamento do serviço para outras especialidades, durante cinco meses, diante da restrição da fase vermelha da COVID-19 no município, atendo somente a casos pontuais referenciados como urgência.

Vale ressaltar que em contrapartida às falas anteriores, outro relato sinalizou a melhora no tratamento com a dispensação da Terapia Antirretroviral (TARV) por um tempo mais prolongado, visto que evita o término da medicação antes da próxima ida ao serviço.

Mudou que eu tô tomando medicamento direto, certo. Antes eu ficava 2 ou 3 dias sem vir aqui buscar o medicamento. Agora não. Eu venho pego 2 e vai acabar amanhã, eu já peguei (P39).

Outro termo citado com alta frequência nesta classe refere-se ao advérbio "ainda", indicando que as mudanças aconteceram e persistem já há algum tempo. Demonstram que restrições na vida das pessoas geram insegurança e o desejo de retorno à normalidade, conforme descrito nos fragmentos textuais abaixo.

\section{Mudou muito. Tá começando a reabrir, mas a missa ainda não começou (P26).}

Mudou. Acabou a missa. Acabaram os lugares. Acabou lazer. Tá voltando. Mas ainda tá bem confuso (P44).

Ainda, a palavra "problema" retrata um contexto relacionado ao trabalho e a própria COVID-19 como mais um problema ameaçador de saúde vivenciado por estas pessoas. Condição essa, que surge exacerbando distúrbios já presentes previamente na vida das PVHIV, como descrito na fala dos participantes.

Na verdade, foi um desvio de função, fui punido e me mandaram pra lá. Por isso que acabou tendo outros problemas e fui aposentado por problemas que originaram não só daí, mas de outras situações também sabe (P21).

Olha eu vejo televisão todos os dias à noite e pela manhã. Eu vejo pela televisão, mas eu, devido a esse problema meu, eu não procuro ficar colocando muita coisa na minha cabeça não (P12).

\section{Classe 2 - Isolamento Social como mudança na rotina diária de PVHIV}

O isolamento e/ou distanciamento social é representado na classe 2 , responsável por $17,7 \%$ dos segmentos de texto, como uma das principais mudanças na rotina dos participantes. Isto foi revelado nas falas por meio das palavras como "dentro" e "casa", que foram fortemente significativas (Qui ${ }^{2} \geq 3,84$ e $p<0,0001$ ), além de outras como "tirar" e "preso" (Qui $\left.{ }^{2} \geq 3,84\right)$. Tais termos apontam um contexto de ações e dificuldades encontradas para o enfrentamento da pandemia da COVID-19, como evidenciado nos segmentos de textos a seguir. 
Praticamente quatro meses dentro de casa. Tirando o fato de ir só ao mercado ou na farmácia, fazer coisas pra ela, coisas assim (P33).

Não saio mais. Eu não percebi muita mudança não. Essa pra mim é a maior. Porque a gente fica preso dentro de casa. Eu trabalho dentro de casa. Tô dando aula on-line, então o negócio mudou muito. Tive que aprender muita coisa (P35).

Em alguns relatos notam-se falas sugestivas de alteração de comportamento e emoções no ambiente domiciliar, desencadeadas pelo isolamento social. O verbo "tirar" aponta que aspectos relacionados à vida social foram suprimidos diante do novo estilo de vida imposto pela pandemia.

Preciso responder? Jesus Misericórdia. Gente eu não aguento ficar dentro de casa. Eu não aguento 24 horas filho na cabeça. Não aguento. Tá tenso. Tá tenso. Mudou meu humor. As meninas falam que eu sou bipolar (P43).

Porque a gente só fica preso. Cara tapada pra ninguém ver. Não pode sair muito. Tirou minha academia, minha igreja, que a gente ia à igreja católica não estou indo mais porque está fechada. Mudou muito (P26).

O termo "sair" em alguns relatos faz referência ao ato de sair de casa como um risco de exposição à COVID-19 associado ao HIV, denotando dúvidas por ter HIV e por vezes o sentimento de medo. Noutra situação, reporta-se como uma restrição imposta pelos filhos para exercer um ato de cuidado e zelo com os pais sabidamente HIV positivo.

Mudou. Agora não saio de casa. Praticamente saio só pra coisas assim bem essenciais e trabalhar (P02).

Eu morro de medo. Eu não sei se por ter HIV isso me prejudica se eu contraio isso aí. Eu fiquei bem assustada. Não estava saindo de casa pra nada. Só assim, eu fui afastada do meu serviço (P23).

Tem que ficar presa. Presa dentro de casa. Meus filhos não deixam sair não. Morrem de medo. Pra mim ir ver a minha mãe é um sacrifício (P37).

\section{Classe 3 - Convívio Familiar e sua organização em tempos de COVID-19}

Diante do isolamento social e consequente restrição de sair de casa, o convívio familiar foi intensificado. Nesta classe, composta com $13,9 \%$ dos segmentos de textos, observa-se a presença do verbo "morar" (Qui $\geq 3,84$ e $p<0,0001$ ) e dos substantivos "irmão", "pai", "mãe" e "filho" (Qui $\left.{ }^{2} \geq 3,84\right)$, aludindo à forma como as famílias se estruturam e como se deu a organização das medidas restritivas e de prevenção no ambiente familiar.
Porque caso alguém tenha dentro de casa a primeira estratégia é quem vai cuidar da gente mesmo. Então vamos tentar não pegar entre si. Atualmente mora eu, minha irmã e meu cunhado. Mas minha mãe e meu pai moram em outra casa e a gente está sempre se vendo é bem próximo. Mudou totalmente, a gente não se toca mais, até ter certeza de que está todo mundo (P21).

Mudou muito. Mora só eu e meu filho. Diminuiu muito, a gente já não tem mais contato com as pessoas como tinha. Mudou porque a gente não tem convívio mais com as pessoas. Se você vai no mercado, tudo é rápido, aquele medo (P30).

Inerente ao convívio familiar, destaca-se a preocupação do cuidado para que a contaminação dos familiares não aconteça. Emergem também alguns conflitos para que os filhos respeitem a condição de risco dos pais que se encontram vulneráveis.

Então fica cada um, por exemplo, eu no meu quarto, meu pai no dele, meu irmão no dele, mas, em comunicação o tempo todo. Se ajudando, isso mudou na rotina. Agora estou mais em casa, mesmo porque meu pai é grupo de risco e eu tô mais em casa (P22).

Pra mim foi mais essa preocupação de não querer levar pra minha família. Hoje eu moro sozinho, mas tenho minha mãe que mora em São João Del Rey, que é uma senhora idosa (P17).

Depois não vem em grupo de oração pedindo, peço oração pra minha mãe que tá entubada, aí embaixo vocês põem lá quem pede é o filho assassino, tá. Eu pego pesado, não é criança mais não. São adultos (P45).

Outro aspecto sinalizado pelos participantes é a alimentação. Relatos de alteração nos hábitos alimentares aparecem como uma mudança significativa referida pelas famílias.

Mudou. Tô comendo muito. Descobri que sei cozinhar. Sei fazer coisas diferentes, descobri isso na pandemia. E ficar em casa (P22).

O período intenso de pandemia vivenciado em família levou a conclusões e permitiu refletir sobre vários eixos do convívio familiar nunca antes percebido. O termo "então" demonstra as conclusões mais relevantes referidas pelos participantes. As falas descrevem sentimentos antagônicos de conflito e aproximação nos relacionamentos familiares.

Trouxe muita aceitação dentro de casa, no sentido de: Quem está com a gente? Estamos sozinhos ou não estamos sozinhos, então houve muita ruptura, em relações interpessoais (P21).

Isso mudou. Minha aproximação é diária, com família e eu, cresceu mais (P22). 


\section{Classe 4 -Aspectos emocionais e estratégias de enfrentamento em tempos de COVID-19}

A classe 4 exibe 12,2\% dos segmentos de textos, apresentando como termos de maior referência $\left(Q u i^{2} \geq 3,84\right.$ ) os verbos como "passar", "querer" e "entender", destacando o sentido das mudanças que aconteceram e o desejo pelo retorno do chamado "normal". Os participantes relatam as emoções que viveram durante a pandemia. Termos como "pior" e "difícil" também foram citados em segmentos com conotação de intensidade.

[...] pode ser mais de outros também de ficar mais em casa, passou a ver coisas que não via quando não estava em casa. Ou que não eram conversadas quando a gente estava naquela coisa de fora (P21).

Não só a minha, mas de várias pessoas do Brasil que estão passando o pior momento de hoje. A pior dificuldade, pior que eu (P31).

[...] Tô muito estressada mesmo. Vai passar. Mas eu me acalmo (P43).

Mudou. Porque a gente fica mais preocupado, porque a gente pensa assim, já é uma pandemia, tá pegando em todo mundo, se pegar em mim, querendo ou não o pensamento meu, a gente já fica esperando uma coisa pior acontecer (P14).

\section{Classe 5 - Mudanças na rotina diária: trabalho e convívio social}

Os relatos desta classe, que reteve $26,1 \%$ de segmentos de textos, através dos termos "rua" (Qui ${ }^{2} \geq 3,84$ e $p<0,0001$ ), "máscara", "buscar" "bar" e "trabalhar" (Qui² $\geq 3,84)$, fazem forte referência às mudanças na rotina diária e, principalmente, com relação ao trabalho. Observa-se uma insatisfação decorrente da restrição de sair na rua somente para atividades essenciais e o desejo de sair como um aspecto social importante para encontrar amigos e conversar.

Eu só saio na rua se necessário, como hoje eu tive que vir no médico (P25).

Ainda está um pouco difícil porque eu sou uma pessoa muito, vamos dizer assim, muito sociável. Gosto de sair, gosto de festa, gosto de trabalhar, às vezes gosto de sentar na rua só pra conversar com os amigos (P11).

As PVHIV vivem a demanda de buscar os medicamentos em datas específicas, o que fortalece a adesão à TARV e esse hábito foi mantido durante a pandemia neste estudo, mesmo diante do medo de sair de casa, dado o reconhecimento da importância do tratamento.

Ah isso já está me deixando doida já menina. Tenho medo de pegar isso, Nossa Senhora. Eu evito de ir em rua. Venho só buscar remédio, só (P09).
No que tange ao trabalho, permeiam várias mudanças influenciadas pela pandemia como o home office, que pouco se conhecia, a redução da jornada de trabalho ou afastamento, e onde é descrito contato com várias pessoas, reafirmando risco por ser uma PVHIV.

Totalmente. Mudou porque principalmente porque eu tava trabalhando, tinha uma carga de trabalho. Tinha um bar, tinha um restaurante que virou um bar depois, e quando eu comecei a movimentar mesmo, que os clientes foram chegando, tive que fechar por causa da pandemia (P33).

Mudou porque estou trabalhando de home office. Desde dia 17 de março. Eu tive algumas vezes. De 15 em 15 dias eu vou fazer o teste na empresa porque se precisar pra poder estar indo, mas, mais mesmo pra acompanhar o diagnóstico. As diretrizes da empresa que me afastaram (P28).

O uso da máscara surge nesta classe como referência à proteção necessária para sair do ambiente domiciliar. Alguns participantes afirmam que se adaptaram à rotina diária $e$ reconhecem a importância da sua utilização, mas verbalizam também as dificuldades e até mesmo a manifestação de sintomas com uso constante da máscara.

Mas no começo eu estava com muito medo de pegar e de sair e ser contaminado. Do jeito que sou azarado eu pego isso aí e morro. Morro no mesmo dia. Estou usando máscara quando eu saio (P03).

A gente fica mais receosa de sair às vezes né. Tem que usar a tal de máscara que é horrível. A gente fica mais cansada do que normal... Porque a respiração da gente fica comprometida (P38).

\section{Classe 6 - Medidas preventivas como forma de redução dos impactos da COVID-19}

Por fim, a classe 6 , responsável por $14,8 \%$ dos segmentos de textos, apresentou uma elevada associação significativa (Qui $^{2} \geq 3,84$ e $p<0,0001$ ) com as seguintes formas ativas, em ordem decrescente: mão, chegar, lavar, doença, banho, álcool, tomar, prevenir e roupa. Portanto, indicam as medidas preventivas para COVID-19 como uma mudança na rotina. Dentre elas destacam-se os cuidados voltados, principalmente, para ambientes externos como a higienização das mãos e o uso de máscara, conforme as falas dos participantes.

Mudou uso de máscara, a higienização das mãos sempre que possível álcool ou lavar as mãos (P18).

Eu fico só assim, tipo estatuto da regra: evito aglomeração, evito sair e evito ficar sem máscara. Lavo muito as mãos, assepsia? Como é o consenso geral que é mesma regra geral que é pra gente fazer (P41). 
Ainda, cuidados ao chegar no ambiente domiciliar, a fim de resguardar, em especial, a saúde dos familiares, foram revelados como importantes preocupações que impactaram em mudanças de comportamento.

Igual chego em casa agora, tiro tudo, lavo tudo, tomo banho, minha esposa... a gente deixa pra fazer tudo junto (P44).

Então assim, eu chego lá na casa da minha mãe, a primeira coisa que faço é tomar banho, tirar a roupa e depois eu vou cumprimentar ela sabe. Porque eu tenho medo de levar doença pra ela (P17).

\section{DISCUSSÃO}

A COVID-19 modificou de forma significativa o cotidiano de toda a população. Entretanto, para as PVHIV, tais efeitos podem ser significativos não apenas nos aspectos psicológicos e sociais de suas vidas, mas também no que se refere aos aspectos biológicos dada a fragilidade de seu sistema imunológico desde o diagnóstico estabelecido, reconhecida pelos participantes desta pesquisa. Representando, assim, um risco aumentado de infecção e complicações relacionadas à COVID-19, além da progressão da doença pelo HIV, em especial nos indivíduos cuja doença não é tratada de forma adequada ${ }^{8}$.

Propostas são discutidas diante da necessidade de agir frente a desafios que surgem ao observar uma possível sindemia, ou seja, duas ou mais epidemias, no caso a COVID-19 e HIV. Ações que vão além de fatores estruturais e vigilância dessas doenças e incluem aspectos biológicos, comportamentais e psicossociais ${ }^{9}$, conforme descritos de forma clara nas falas.

O isolamento e/ou distanciamento social é a principal medida de prevenção adotada por todos os países no mundo durante a pandemia. Contudo, as PVHIV necessitam de acompanhamento de saúde regular para, por exemplo, realizar o monitoramento semestral de CD4 e Carga Viral, buscar medicações destinadas ao tratamento, além de tratar doenças oportunistas, comumente presente junto às PVHIV. Logo, o tratamento correto do HIV e até mesmo de outras doenças atreladas a ele, como foi evidenciado nesta pesquisa, pode, por vezes, vir a ser interrompido ou prejudicado diante de tal medida preventiva ${ }^{8}$

Diante disso, desafios enormes permeiam a manutenção dos cuidados e assistência geral às PVHIV. Estes vão desde o acesso aos testes, atraso para iniciar a TARV e bloqueios de cidades que retardam a continuação e alocação de recursos para as pessoas. Portanto, a Organização Mundial de Saúde (OMS), UNAIDS e a Rede Global de PVHIV propuseram estratégias e dentre elas a dispensação da TARV em doses de 3 a 6 meses para reduzir as visitas aos centros de tratamento, conforme visto em uma das falas dos participantes. Assim, garantem o fornecimento de medicamentos e também de insumos, como preservativos, facilitando, dessa forma, a não interrupção do tratamento e favorecendo a redução de danos em potencial.
Diversas frentes de estudo sugerem que a interrupção da TARV pode ocasionar não só alterações na saúde física, mas também questões relacionadas à saúde mental ${ }^{10}$.

Cabe destacar que no presente estudo não foi identificado prejuízo no tratamento direto ao HIV, visto que a maioria destacou sair de casa somente para retirada dos medicamentos. Entretanto, o tratamento de doenças oportunistas, como o HPV no relato de um dos participantes, foi prejudicado, o que pode impactar negativamente na saúde deste usuário.

A pandemia marcou um contexto que traz à tona a diversidade e complexidade do convívio familiar. A convivência imposta pelo distanciamento social e do slogan "Fique em casa" contribuiu para aproximação de pessoas e ao mesmo tempo conflitos, rupturas e reflexões sobre morte e finitude ${ }^{11}$. Tais achados também foram encontrados nos relatos dos participantes desta pesquisa que sinalizam a preocupação em tomar os cuidados preconizados buscando prevenir o contágio e transmissão da COVID-19 para os familiares, sendo esta, também, uma das fontes de conflitos existentes no período de isolamento.

Outra mudança que aparece no contexto familiar advinda do isolamento social é a alimentação. Em geral, as PVHIV são orientadas a melhorar sua alimentação visando fortalecer o sistema imunológico. Com mais tempo em casa, as pessoas passaram a se dedicar preparando sua alimentação e, assim, tiveram a oportunidade de ter uma alimentação saudável ${ }^{12}$.

Embora o isolamento e/ou distanciamento social tenham o objetivo de beneficiar a saúde física da população, essa diretriz pode ser prejudicial à saúde social e emocional. Dessa forma, nota-se que o aumento da ansiedade tem sido prevalente em todo o mundo ${ }^{8}$. O CDC observou que indivíduos com doenças crônicas, como o HIV, podem desenvolver uma resposta ao estresse mais forte do que o resto da população, decorrente do risco aumentado de contrair COVID-19 devido ao sistema imunológico comprometido ${ }^{13}$, o que converge com os achados desse estudo.

Sabe-se que PVHIV têm maior probabilidade de desenvolver depressão do que aquelas sem o vírus ${ }^{14}$. Portanto, o distanciamento social necessário para combater COVID-19 pode aumentar a solidão, diante da falta de convívio social, podendo exacerbar os sintomas depressivos na população geral, mas especialmente PVHIV, principalmente os indivíduos recém-diagnosticados ${ }^{8}$, não incluídos nesta pesquisa. Assim, cabe destacar a necessidade de ações voltadas ao estresse relacionado à COVID-19, pois repercutem no sofrimento mental da população por meio de transtornos como a depressão e ansiedade, já mencionados anteriormente.

Pesquisa aponta que o método de telessaúde, empregado como coleta de dados, tem fornecido uma opção para ajudar as pessoas em tempos difíceis de isolamento. Os achados descrevem que sentimentos como solidão e estresse foram obtidos em relatos por contato telefônico. Relatando, também, a possibilidade de ajuda às PVHIV ao oferecer apoio e direcionamento, mantendo-as conectadas a um sistema de saúde ${ }^{15}$. 
Sabe-se que o trabalho tem forte relação na vida das pessoas. Está presente nas mudanças de rotina e têm enorme importância tanto nas relações pessoais, sociais e econômicas. $O$ exercício do chamado "home office" já existe no mundo do trabalho, contudo sua prática era uma exceção que acabou se tornando regra para diversos ramos de atividades durante a pandemia, inclusive para alguns participantes desta pesquisa. $\mathrm{O}$ ambiente domiciliar passou a dividir espaço com trabalho, atividades escolares, domésticas e lazer. Surgem então diversos desafios: as pessoas se manter "on-line" e responsivas, desenvolverem aprendizado rápido de novas tecnologias e comunicação, aprimorarem a gestão do tempo e atender as demandas de trabalho empresariais. Tudo isso respeitando espaço do convívio familiar, momentos de lazer e reabilitação física e mental no ambiente domiciliar ${ }^{16}$.

No que se refere às medidas preventivas realizadas pelos entrevistados, destaca-se, principalmente, o isolamento social, já discutido anteriormente, o uso de máscara e higienização das mãos com sabão ou álcool a 70\%, bem como a higienização de roupas e corpo ao entrar em contato com locais potencialmente contaminados. Nota-se uma amplificação de tais práticas por estes indivíduos diante da condição crônica relacionada a sua fragilidade imunológica. Tais práticas, bem como o cuidado redobrado com sua condição de saúde, convergem com as recomendações fundamentais para conter a rápida transmissão da COVID-1917,18.

\section{CONCLUSÕES E IMPLICAÇÕES PARA A PRÁTICA}

Diante dos achados, nota-se que a pandemia da COVID-19 impactou em diversas mudanças na rotina diária de PVHIV, conforme relataram os participantes, desde o ambiente de trabalho e de lazer, até o convívio familiar, aspectos emocionais individuais e de tratamento. Cabe destacar que o isolamento social, uma das principais medidas preventivas recomendadas, foi o responsável pelo desencadeamento da maioria das mudanças relatas, principalmente as relacionadas aos aspectos emocionais e psicológicos vivenciados durante este período.

Logo, muitos desafios demonstraram serem vivenciados pelos participantes diante deste cenário mundial. Para tal, estratégias de enfrentamento foram apontadas como forma de minimizar tais impactos. Dentre estas, o acesso e manutenção do tratamento correto e ininterrupto com à TARV, por meio da disponibilização para um período maior de tempo, visando garantir uma boa qualidade de vida. Além disso, o uso de medidas preventivas, como a utilização de máscara e isolamento social, se tornaram parte do dia-a-dia da população como um todo, mas em especial das PVHIV, a fim de mitigar as repercussões da COVID-19 na saúde destes indivíduos que pertencem ao grupo de risco.

O estudo apresenta limitações quanto aos dados pelo único contexto geográfico definido. Desse modo, torna-se necessário a realização de mais estudos acerca do fenômeno estudado que apresentem realidades sociais diversas e que agreguem mais conhecimentos, para além dos novos achados apresentados.
A pesquisa apresenta contribuições para o avanço do conhecimento científico na área da saúde, incluindo também a enfermagem, ao identificar as mudanças na rotina diária das PVHIV diante da pandemia da COVID-19 no cenário brasileiro, um contexto ainda pouco explorado, evidenciando importantes questões relativas as reais adversidades e estratégias de enfrentamento vivenciadas por essa população. Assim, tornar-se-á possível a elaboração de planos de orientações, políticas públicas e estratégias gerenciais e assistenciais que promovam uma reorganização dos processos assistenciais em saúde para o para o enfrentamento desse agravo.

\section{CONTRIBUIÇÕES DOS AUTORES}

Desenho do estudo. Tassiana Maria Vieira Pereira. Elucir Gir. Coleta ou produção dos dados. Tassiana Maria Vieira Pereira. Análise de dados. Tassiana Maria Vieira Pereira. Andressa Silva Torres dos Santos. Interpretação dos resultados. Tassiana Maria Vieira Pereira. Elucir Gir. Andressa Silva Torres dos Santos.

Redação e revisão crítica do manuscrito. Tassiana Maria Vieira Pereira. Elucir Gir. Andressa Silva Torres dos Santos.

Aprovação da versão final do artigo. Tassiana Maria Vieira Pereira. Elucir Gir. Andressa Silva Torres dos Santos.

Responsabilidade por todos os aspectos do conteúdo e a integridade do artigo publicado. Tassiana Maria Vieira Pereira. Elucir Gir. Andressa Silva Torres dos Santos.

\section{EDITOR ASSOCIADO}

\author{
Antonio José de Almeida Filho (1)
}

\section{EDITOR CIENTÍFICO}

\author{
Ivone Evangelista Cabral
}

\section{REFERÊNCIAS}

1. World Health Organization. Coronavirus Disease (COVID-19) Dashboard [Internet]. Geneva: WHO; 2020 [citado 2021 Jan 27]. Disponível em: https://covid19.who.int/

2. Moraes EB, Valente GSC, Souza DF, Sanchez MCO. A segurança dos profissionais de saúde em tempos de COVID-19: uma reflexão. Res Soc Dev. 2020;9(7):1-15. http://dx.doi.org/10.33448/rsd-v9i7.3832.

3. Mirzaei H, McFarland W, Karamouzian M, Sharifi H. COVID-19 among people living with HIV: a systematic review. AIDS Behav. 2021 jan;25(1):8592. http://dx.doi.org/10.1007/s10461-020-02983-2. PMid:32734438.

4. Marziali ME, McLinden T, Card KG, Closson K, Wang L, Trigg J et al Social isolation and mortality among people living with HIV in British Columbia, Canada. AIDS Behav. 2021;25(2):377-88. http://dx.doi. org/10.1007/s10461-020-03000-2. PMID: 32797358.

5. Nascimento LCN, Souza TV, Oliveira ICS, Moraes JRMM, Aguiar RCB Silva LF. Theoretical saturation in qualitative research: an experience report in interview with schoolchildren. Rev Bras Enferm. 2018;71(1):22833. http://dx.doi.org/10.1590/0034-7167-2016-0616. PMid:29324967.

6. Souza MAR, Wall ML, Thuler ACMC, Lowen IMV, Peres AM. O uso do software IRAMUTEQ na análise de dados em pesquisas qualitativas. Rev Esc Enferm USP. 2018;52:e03353. http://dx.doi.org/10.1590/ S1980-220X2017015003353. PMid:30304198. 
7. Minayo MCS. O desafio do conhecimento: pesquisa qualitativa em saúde. 14ª ed. São Paulo (SP): Hucitec; 2014.

8. Chenneville T, Gabbidon K, Hanson P, Holyfield C. The Impact of COVID-19 on HIV treatment and research: a call to actio. Int J Environ Res Public Health. 2020;17(12):4548. http://dx.doi.org/10.3390/ijerph17124548. PMid:32599783.

9. Shiau S, Krause KD, Valera P, Swaminathan S, Halkitis PN. The Burden of COVID-19 in people living with HIV: a syndemic perspective. AIDS Behav. 2020;24(8):2244-9. http://dx.doi.org/10.1007/s10461-02002871-9. PMid:32303925.

10. Jiang H, Zhou Y, Tang W. Maintaining HIV care during the COVID-19 pandemic. Lancet HIV. 2020;7(5):e308-9. http://dx.doi.org/10.1016/ S2352-3018(20)30105-3. PMid:32272084.

11. Heilborn MLA, Peixoto CE, Barros MML. Tensões familiares em tempos de pandemia e confinamento: cuidadoras familiares. Physis. 2020;30(2):e300206. http://dx.doi.org/10.1590/s0103-73312020300206.

12. Justo GF. A percepção do nutricionista sobre os hábitos alimentares de pacientes em trabalho "home office" durante a pandemia da Covid-19. um relato de experiência. Rev Alim Cult Américas. 2020;2(2):245-51. http://dx.doi.org/10.35953/RACA.V2I2.89.

13. Centers for Disease Control and Prevention. Coping with stress [Internet]. USA: CDC; 2020 [citado 2021 Jan 27]. Disponível em: https://www.cdc. gov/coronavirus/2019-ncov/daily-life-coping/managing-stress-anxiety. $\mathrm{html}$
14. Nacher M, Adriouch L, Godard Sebillotte C, Hanf M, Vantilcke V, El Guedj $M$ et al. Predictive factors and incidence of anxiety and depression in a cohort of HIV-positive patients in French Guiana. AIDS Care. 2010;22(9):1086-92. http://dx.doi.org/10.1080/09540121003599232. PMid:20824561.

15. Algarin AB, Varas-Rodríguez E, Valdivia C, Fennie KP, Larkey L, Hu $\mathrm{N}$ et al. Symptoms, stress, and HIV-related care among older people living with HIV during the COVID-19 pandemic, Miami, Florida. AIDS Behav. 2020;24(8):2236-8. http://dx.doi.org/10.1007/s10461-02002869-3. PMid:32303923.

16. Losekann RGCB, Mourão HC. Desafios do teletrabalho na pandemia COVID-19: quando o home vira office. Cad Administração. 2020;28(esp.):725 http://dx.doi.org/10.4025/cadadm.v28i0.53637.

17. World Health Organization. Coronavirus disease (COVID-19) advice for the public [Internet]. Geneva:WHO;2020 [citado 2021 Jan 27]. Disponíve em https://www.who.int/emergencies/diseases/novel-coronavirus-2019/ advice-for-public

18. Wilder-Smith A, Freedman DO. Isolation, quarantine, social distancing and Community containment: pivotal role for old-style public health measures in the novel coronavirus (2019-nCoV) outbreak. J Trave Med. 2020;27(2):taaa020. http://dx.doi.org/10.1093/jtm/taaa020. PMID: 32052841 